\title{
Industry dynamics, technological regimes and the role of demand
}

\author{
Isabel Almudi • Francisco Fatas-Villafranca • \\ Luis R. Izquierdo
}

(C) Springer-Verlag Berlin Heidelberg 2013

\begin{abstract}
In this paper, we propose an industrial dynamics model to analyze the interactions between the price-performance sensitivity of demand, the sources of innovation in a sector, and certain features of the corresponding pattern of industrial transformation. More precisely, we study market concentration in different technological regimes and demand conditions. The computational analysis of our model shows that market demand plays a key role in industrial dynamics. Thus, although for intermediate values of the price-performance sensitivity, our results show the wellknown relationships in the literature between technological regimes and industry transformation, we find surprising outcomes when demand is strongly biased either towards price or performance. Hence, for different technological regimes, a high performance sensitivity of demand tends to concentrate the market. On the other hand, under conditions of high price sensitivity, the industry generally tends to atomize. That is to say, for extreme values of the price-performance sensitivity of demand, we find concentrated or atomized market structures no matter the technological regime we are in. These results highlight the importance of considering the role of demand in the analysis of industrial dynamics.
\end{abstract}

Keywords Industrial dynamics · Demand · Technological regimes · Evolutionary economics

JEL Classification O33 · B52

I. Almudi $(\bowtie) \cdot$ F. Fatas-Villafranca

University of Zaragoza, Zaragoza, Spain

e-mail: ialmudi@unizar.es

L. R. Izquierdo

University of Burgos, Burgos, Spain 


\section{Introduction}

Over the last three decades, the realm of industrial dynamics has progressed significantly (Malerba 2007). One of the most active lines of research has tried to find causal links between technological regimes and the dynamics of innovative industries (Nelson and Winter 1982; Dosi 1988; Malerba and Orsenigo 1993, 1996; Marsili 2001). This body of works has drawn upon the fact that technological learning in different industrial activities differs in the following factors:

(i) The level of technological opportunities. It is a well-known fact that different activities and sectors enjoy a different scope and ease for technological progress.

(ii) The degree of cumulativeness in the production of new knowledge. This aspect defines to what extent technical solutions are incrementally built upon those already achieved by a firm.

(iii) The appropriability conditions. That is, the factors which determine the ease with which innovation results are protected against competitors. Marsili $(1999,2001)$ sharpens the notion of appropriability by drawing upon previous contributions by Pavitt et al. (1989). Thus, Marsili distinguishes between two types of appropriability mechanisms: firstly, those factors that preserve innovators from being imitated by competitors from inside and outside the industry (patents, secrecy, tacitness); secondly, those technological characteristics which make it difficult for external firms to enter the sector. We may refer to the former appropriability conditions as barriers to imitation, and to the latter as technological entry barriers or barriers for innovative entry.

The aforementioned aspects define different types of technological regimes.

From a formal-theoretical perspective, Winter (1984) proposed, in his classical paper on technological regimes and industrial dynamics, that the entrepreneurial vs routinized mode of innovation in an industry-i.e. the specific character of the technological regime - could determine the evolution pattern of the industry in very specific ways. These relationships have also been explored theoretically and empirically by Dosi et al. (1995), and Breschi et al. (2000). Both the theoretical and the empirical contributions point to certain relationships between entrepreneurial regimes (open and permeable techno-institutional conditions favoring the emergence of new agents) and patterns of industry evolution akin to creative destruction (characterized by a high number of firms, a low industry concentration and a key role played by new entrants $v s$ incumbent innovators). On the other hand, it has been suggested that routinized regimes (those showing techno-institutional conditions favoring incumbent innovators) could lead to creative accumulation patterns (characterized by higher concentration levels, a lower number of firms and consolidated incumbents leading innovation).

Undoubtedly, the literature on technological regimes and sectoral dynamics has shed new light on the reasons for the uneven evolution of industrial activities in modern economies. Nevertheless, recent contributions by Malerba (2006), Klepper and 
Malerba (2010), Bresnahan and Yin (2010) or Dosi and Nelson (2010) suggest that, although we have achieved significant advances along these lines, it may be time to explore the interplay between knowledge-related aspects of innovation and demanddriven mechanisms of market competition. To this regard, in this paper we propose an evolutionary model of industrial dynamics to analyze market concentration and leadership shifts in different technological regimes and demand conditions.

Our model lies in the tradition of Nelson and Winter (1982)—see also Metcalfe (1998), Dosi (2001) or Silverberg and Verspagen (2005)—and it incorporates entry/exit mechanisms, innovation, imitation, competition, strategic learning and firm growth in an innovative industry. We assume that price-setting (for-profit) firms compete in questions of price and product performance. They improve their products through R\&D-based innovation activities, and they do so both by carrying out inner activities of knowledge creation, and by imitating their competitors to assimilate their existing knowledge. Firms also update their R\&D investment routines through a learning mechanism with a stochastic component. An important feature of our model is that we conceive global demand transformation as a gradual process driven by users/consumers' learning and by firms' competitiveness (in price and performance). Thus, the process of demand transformation indicates the rhythm of the output and capacity growth of firms.

It is worth pointing out that our model's analysis incorporates the notion of a technological regime to characterize different learning and innovation conditions in different sectors. The level of technological opportunities, cumulativeness, and appropriability conditions - in the form of both barriers to imitation and barriers to innovative entry (Marsili 1999) - appear in the model. On the demand side, the price-performance sensitivity of demand plays a key role in the model. This factor is explicitly mentioned by Klepper and Malerba (2010; p. 1516) and, drawing upon the taxonomical study of Keith Pavitt, by Dosi and Nelson (2010; p. 87). In fact, these authors distinguish between sectors whose demand is price-sensitive (agrofood, consumer durables), performance-sensitive (medical instruments, industrial machinery), or mixed (electronics or chemicals).

As we will see, the computational analysis of the model shows that market demand plays a key role in industrial dynamics. Thus, although for intermediate values of the price-performance sensitivity of demand our results reproduce well-known relationships in the literature - entrepreneurial vs. routinized regimes leading to creative destruction vs. creative accumulation-, we find surprising outcomes when demand is strongly biased either towards price or performance. Hence, for very different technological regimes, a high performance sensitivity of demand tends to concentrate the market. On the contrary, under conditions of high price sensitivity, the industry tends to atomize. Therefore, our model seems to indicate that the well-known relationships between industrial dynamics and technological regimes (found in the literature) might only emerge under certain demand conditions.

Our paper is organized as follows: we present our model in Section 2. In Section 3, we offer a general overview of the model feedbacks and theoretical mechanisms. In Section 4 , we focus on the computational analysis of the model to clarify the role of 
demand in alternative technological regimes. Here we find that the well-known relationships between technological regimes and industrial dynamics only emerge under certain demand conditions in the model. Finally, we summarize our conclusions.

\section{The model}

\subsection{The competitiveness of firms}

Let us assume that there are $n(i=1, \ldots, n)$ firms competing in an innovative industry with price ${ }^{1} p_{i t}$ and product performance $x_{i t}$ (quality, reliability, size, speed, precision). Regarding prices, we will assume that firms set prices by applying a markup over their unit cost (the greater their market power, the higher the mark-up). With $m\left(s_{i t}\right)$ being a function including the mark-up set by each firm depending on its market share ${ }^{2}$ and $c_{i t}$ the total cost per output unit, we suppose that:

$$
p_{i t}=m\left(s_{i t}\right) c_{i t}, \quad m\left(s_{i t}\right) \geq 1, \quad m(0)=1, \quad m^{\prime}>0
$$

For simplicity, we will consider the following pricing routine (Almudi et al. 2012; Fatas-Villafranca and Saura 2004):

$$
p_{i t}=\left(1+s_{i t}\right) c_{i t},
$$

From Eq. 1, it is straightforward that firm $i$ 's unit profit is

$$
\pi_{i t}=s_{i t} c_{i t}
$$

Regarding performance $\left(x_{i t}\right)$, we will establish, later, how firms improve their products through R\&D-based technological innovations. For now, given the vector $\left(p_{i t}, x_{i t}\right)$, we define the level of competitiveness of firm $i$ (as perceived by the consumers/users in the market) as follows:

$$
\begin{aligned}
\gamma_{i t} & =(1-\alpha) \frac{x_{i t}-\bar{x}_{t}}{\bar{x}_{t}}-\alpha \frac{p_{i t}-\bar{p}_{t}}{\bar{p}_{t}}, \quad \alpha \in(0,1) \\
\bar{x}_{t} & =\frac{\Sigma x_{j t}}{n} ; \bar{p}_{t}=\frac{\Sigma p_{j t}}{n}
\end{aligned}
$$

Parameter $\alpha$ represents the price-performance sensitivity of demand. In Eq. 3 we assume that any firm $i$ is more competitive in the market, the better its product performance, and the lower its price. In addition, let us note that competitiveness in price (and performance) is measured in relation to the average price (and performance) in the market.

\footnotetext{
${ }^{1}$ We use physical capital as numerary.

${ }^{2}$ See Ariga et al. (1999) for interesting empirical evidence on market shares as determinants of firms' mark-ups.
} 


\subsection{Demand transformation and production}

There is demand-driven production and firm growth in our model. Regarding the demand-side of the market, we shall consider that the total market demand $\left(Q_{t}^{d}\right)$ is constant. For simplicity we normalize it with a value of 1 . That is: ${ }^{3}$

$$
Q_{t}^{d}=Q=1
$$

Likewise, with $s_{i t}$ being the proportion of global demand supplying firm $i$ at moment $t$ - that is, its market share-we see that the instantaneous demand of firm $i$ will be:

$$
Q_{i t}^{d}=s_{i t} Q=s_{i t}
$$

That is to say, the demand of firm $i$ coincides with its market share. If we now consider that the consumers/users interact with and observe each other, and spread and share information regarding the prices and performances of the different products, we can suppose that there is a gradual process of demand transformation. Consumers will retire their demand from certain firms and give it to those with a higher level of $\gamma_{i t}$ In a recent paper, Fatas-Villafranca et al. (2011) propose explicit evolutionary microfoundations to capture this kind of processes, and obtain a typical replicator dynamics expression. Along these lines, and drawing also on Metcalfe (1998), we propose that the process of demand transformation in the model can be represented as:

$$
\begin{aligned}
g_{i t}^{d} \equiv & \frac{Q_{i t+1}^{d}-Q_{i t}^{d}}{Q_{i t}^{d}}=\frac{s_{i t+1}-s_{i t}}{s_{i t}}=\gamma_{i t}-\bar{\gamma}_{t}, \quad i=1, \ldots, n \\
& \text { with } \bar{\gamma}_{t}=\sum_{j=1}^{n} s_{j t} \gamma_{j t} .
\end{aligned}
$$

Equation 5 establishes that those firms with competitiveness levels higher than the (share-weighted) average levels will experience positive demand growth rates, and increase their market share.

Additionally, we assume that each firm's rate of growth fits the growth rate of its demand given by Eq. 5. Therefore, if we suppose that all firms produce in accordance with a technology:

$$
Q_{i t}^{s}=K_{i t}
$$

and assuming that $Q_{i t}=Q_{i t}^{s}=Q_{i t}^{d}, \forall t$, the following must be fulfilled:

$$
g_{i t} \equiv \frac{Q_{i t+1}-Q_{i t}}{Q_{i t}}=g_{i t}^{s}=g_{i t}^{k} \equiv \frac{K_{i t+1}-K_{i t}}{K_{i t}}=g_{i t}^{d}=\frac{s_{i t+1}-s_{i t}}{s_{i t}}
$$

\footnotetext{
${ }^{3}$ We make this simplifying assumption to focus on the analysis of the market competitive process. In Almudi et al. (2012) we consider growth and analyze its effects on industrial dynamics.
} 
From the above-mentioned it is clear that: ${ }^{4}$

$$
Q=\sum_{j=1}^{n} Q_{j t}^{s}=\sum_{j=1}^{n} K_{j t}=K=1
$$

\subsection{R\&D spending}

We shall suppose that in each time period, firms will spend on R\&D a proportion $r_{i t} \in[0,1]$ of the profits obtained in the previous time period. Therefore, firm $i$ 's R\&D spending at any time will be:

$$
R_{i t+1}=r_{i t} \pi_{i t} Q_{i t}
$$

Clearly, $r_{i t}$ is a firm-specific operating routine. According to Silverberg and Verspagen (2005), deciding the most convenient level of $r_{i t}$ has traditionally been considered to be a highly uncertain strategic choice. Therefore, instead of assuming that $r_{i t}$ is calculated by applying any optimizing procedure, we will consider that firms adapt this routine by trying to imitate the behavior of their most successful rival in a percentage $\beta$. We assume that there is a random component $\left(\varepsilon_{i t}\right)$ introducing a certain lack of precision in the perception of the target to imitate. More precisely, we will consider that firms update $r_{i t}$ according to the following expression: ${ }^{5}$

$$
r_{i t+1}=r_{i t}+\beta\left(\left\langle r_{t}^{*}+\varepsilon_{i t}\right\rangle-r_{i t}\right), \quad \beta \in[0,1], \varepsilon_{i t} \sim N(0, \sigma)
$$

We denote by $r_{t}^{*}$ the $\mathrm{R} \& \mathrm{D}$ routine of the most profitable firm at any time $\left(r_{t}^{*}=\right.$

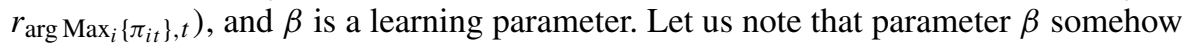
determines a higher or lower strategic stability of the firms in the sector. Parameter $\sigma$ can be interpreted as both an indicator of strategic/informational fuzziness - as firms will be visualising target $r_{t}^{*}$ less precisely, the higher the value of $\sigma-$, as well as in terms of volatility, given that the most profitable firm will alter its behavior more abruptly, the higher the value of $\sigma$. Highly innovative industries are affected by high levels of uncertainty. This justifies that even the most profitable firm at any given time can consider changing their behavior, modifying $r_{t}^{*}$.

Finally, firm $i$ 's unit cost will be:

$$
c_{i t}=1+\frac{R_{i t}}{Q_{i t}}=1+r_{i t-1} \pi_{i t-1} \frac{Q_{i t-1}}{Q_{i t}}
$$

\footnotetext{
${ }^{4}$ That is, there is a constant stock of physical capital $K=1$, and we suppose that firms hire the capital they need to satisfy demand at any given moment. So, if a firm gains market share, it will hire additional units of capital, but if it loses share, it will stop hiring those units it no longer needs. Moreover, as $Q=\Sigma Q_{j t}$ and $K=\Sigma K_{j t}$, it is clear that, $s_{i t} \equiv \frac{Q_{i t}}{Q}=\frac{K_{i t}}{K}$. Likewise, since $Q=K=1$, it follows that $s_{i t}=Q_{i t}=K_{i t}$. ${ }^{5}$ Where,

$$
\langle r\rangle=\left\{\begin{array}{cc}
0 & r<0 \\
r & 0 \leq r \leq 1 \\
1 & 1<r
\end{array}\right\}
$$
}




\subsection{Product innovation}

Expression 10 below is, basically, an innovation equation inspired in Nelson (1982), where $R_{i t}$ is the spending on R\&D and $z_{i t}$ is R\&D productivity.

$$
x_{i t+1}-x_{i t}=z_{i t} x_{i t}^{\eta} R_{i t}
$$

Where

$$
\begin{aligned}
& z_{i t}=\phi\left(\frac{x_{t}^{\mathrm{Max}}-x_{i t}}{x_{i t}}\right)+u_{i t}, \quad u_{i t} \sim \Gamma\left(u_{\min }, u_{\text {mode }}, u_{\mathrm{Max}}\right) \\
& \phi \in[0,1] ; u_{\min }=u_{\text {mode }}=0 ; u_{\text {Max }} \in[0,1] \\
& \eta \in[0,1]
\end{aligned}
$$

The expression $\Gamma\left(u_{\min }, u_{\text {mode }}, u_{\mathrm{Max}}\right)$ is the density function of a triangular probability distribution. It is clear that parameter $u_{\mathrm{Max}}$ is an indicator of the level of technological opportunities in the industry. The greater this parameter, the higher the probability that the R\&D productivity of any firm will show large and positive shocks.

In Eq. 10, we are assuming that the productivity of R\&D depends on the acquisition of new knowledge which comes from two complementary sources: inner research activities-with a firm-idiosyncratic innovative output captured by $u_{i t}$ in Eq. 10 - and, imitation, through which firms assimilate existing knowledge already produced by their competitors in the industry. This element is captured by the gapexpression in Eq. 10. It is straightforward to interpret the parametric value of $\phi$ as an indicator of the higher or lower appropriability of new knowledge in the industry. More precisely, through this parameter we capture the barriers to imitation in the sense of Marsili (1999). So, the higher the value of $\phi$, the lower the barriers to imitation, and low values of $\phi$ will correspond to high imitation barriers in the industry (secrecy, tacitness, patents).

Finally, let us mention that parameter $\eta$ captures the degree of cognitive cumulativeness in the industry (Rosenberg 1976). In fact, Eq. 10 incorporates two mechanisms that may be associated with cumulativeness:

Firstly, the factor $x_{i t}^{\eta}$. Clearly, the higher the value of parameter $\eta$ is, the more the technical solutions to innovative problems are incrementally built upon knowledge already achieved by the firm (this previous knowledge is enclosed in $x_{i t}$ ). Following Rosenberg (1976), we believe that this self-reinforcing aspect of cognitive processes is very important. In fact, we will assume high cognitive cumulativeness $(\eta=1)$ as an almost permanent assumption in our model. ${ }^{6}$ To this regard, we draw upon previous contributions by Romer (1990) or, in the evolutionary tradition, Fatas-Villafranca et al. (2009).

\footnotetext{
${ }^{6} \mathrm{We}$ are grateful for the referees' comments regarding cumulativeness in Eq. 10. Although we shall concentrate on the case of high cumulativeness, an exhaustive exploration of the role of $\eta \in[0,1]$ opens up lines for future research. To illustrate this point, we will explore some aspects of our model related to low cumulativeness in Section 4.1.2 and in the Appendix 2.
} 
Secondly, the factor $R_{i t}$ introduces in Eq. 10 a success-breeds-success mechanism coming from the way in which $\mathrm{R} \& \mathrm{D}$ activities are funded in the model. ${ }^{7}$ The significance of this mechanism has been highlighted by Malerba and Orsenigo (1993, 1996.

\subsection{Exit and entry of firms}

Any firm $i$ whose capital $K_{i t}$ falls below a minimum quantity ${ }^{8}$ exits the market. On the other hand, new firms can enter the market. At every time step, we assume that there is a certain probability that, at the most, one new firm enters the sector. ${ }^{9}$ Likewise, we assume that such a probability is higher, the greater the maximum profit is in the sector. To be specific, we consider that the probability of this event occurring is:

$$
\begin{aligned}
P\left(E_{t}=1\right)= & \frac{(1-\lambda) \pi_{t}^{\operatorname{Max}}}{1+\pi_{t}^{\operatorname{Max}}} \\
& \text { with } \lambda \in[0,1] .
\end{aligned}
$$

where $E_{t}$ is a random variable that represents the number of new entrants (either 0 or 1) at time $t$, and $\pi_{t}^{\mathrm{Max}}$ represents the maximum profit achieved by a firm at $t$. It is worth noting that parameter $\lambda$ can be interpreted as an indicator of the entry barriers in the industry. Although the notion of entry barriers is rather general, we will consider here interpretations of this parameter from a knowledge-based approach. In this regard, parameter $\lambda$ may include the so-called technological entry barriers (Marsili 2001). Let us recall that high technological entry barriers in a sector can arise from the new entrants' need to manage different fields of knowledge (Winter 1987). Additionally, the need to combine technological capabilities and complementary assets to gain access to certain sectors may also reinforce the barriers to innovative entry (Teece 1986). In any case, regarding our model, the higher the value of $\lambda$, the stronger the entry barriers in the industry.

Additionally, we suppose that the new entrant will have an initial capital given by:

$$
K_{n+1} \sim \mathrm{U}\left(0, K^{\text {maxEntry }}\right)
$$

Where $K^{\text {maxEntry }}$ is an exogenous parameter, and $\mathrm{U}$ denotes the continuous uniform probability distribution. Let us note that, after assigning the initial capital to the new entrant, all capitals are normalized, so they all add up to one. Thus, at all times, any firm's capital is equal to its market share.

Finally, we assume that the new entrant randomly chooses one of the existing incumbent firms to replicate its level of performance, and its $R \& D$ to profits ratio.

\footnotetext{
${ }^{7}$ Another extension of our model would involve introducing a parameter in Eq. 10 to control the impact of the success-breeds-success mechanism in R\&D funding. We are also grateful to the referees for this suggestion. We shall leave this extension for future research, since it implies reflecting on the R\&D to size relationship, or the possible existence of diminishing returns to R\&D. See Klepper (1996) or Cohen and Klepper (1996).

${ }^{8}$ The minimum capital in our computational experiments is $10^{-6}$.

${ }^{9}$ Every time a firm enters or exits the market, the sum of all capitals is normalized to 1 .
} 
We shall suppose that the probability of an incumbent being selected for replication is proportional to its market share.

\section{Overview of the dynamics}

Before looking at the computational analysis, we shall briefly consider the feedbacks and theoretical mechanisms of the model. Figure 1 schematically represents the dynamics of the model. The variables that are more closely related to costs and prices are placed on the left, whilst the variables more closely related to the processes of innovation and performance improvement appear towards the right.

Firstly, we notice that the dynamics of the model are characterized by the trajectories of the fundamental variables $s_{i t}, r_{i t}, x_{i t}$. From these fundamental trajectories we can obtain the trajectories of the other variables. Figure 1 shows positive feedbacks in black and negative ones in grey. The dashed lines represent the variables affected after a delay.

As we know, firms compete on prices and product performance. Both factors make up a firm's competitiveness. The greater this is, the greater a firm's growth in terms of

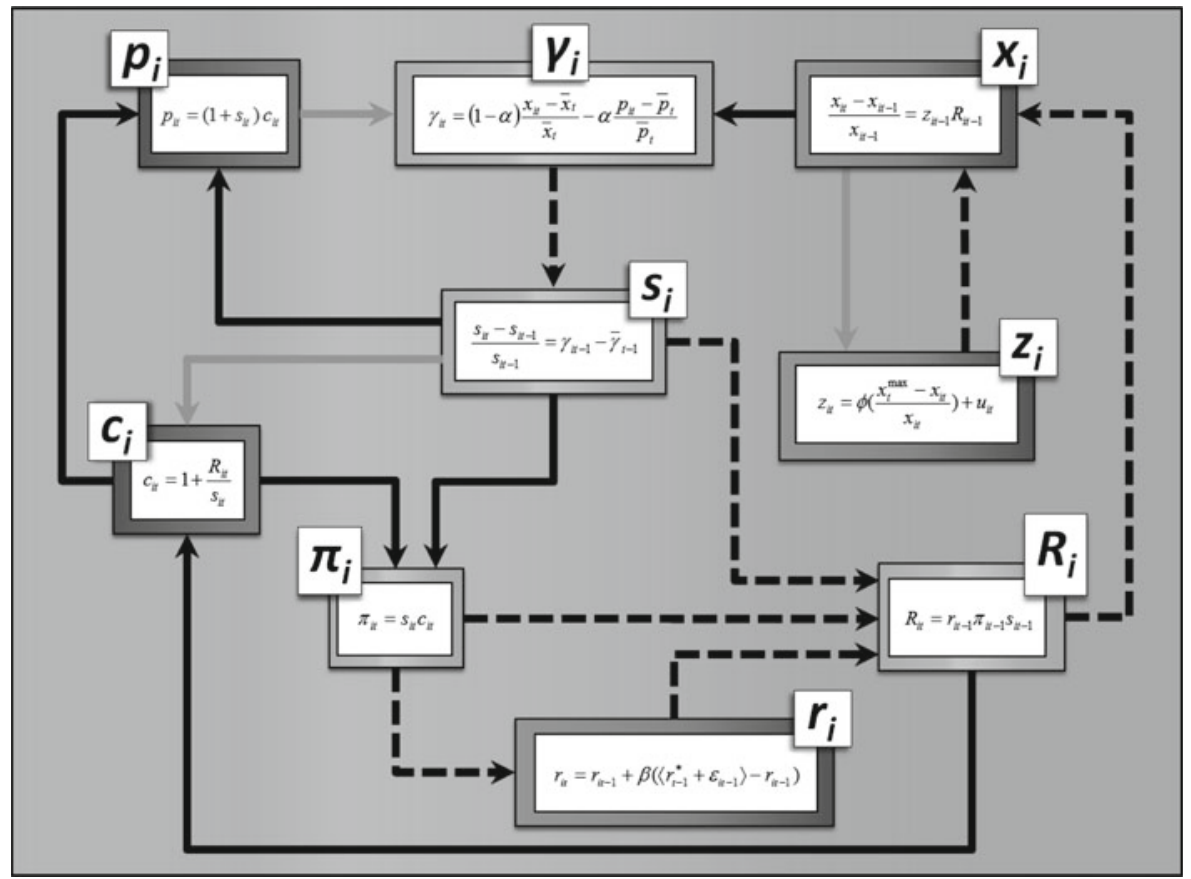

Fig. 1 Overview of the interactions between the variables in the model. A solid black arrow from $\mathrm{X}$ to $\mathrm{Y}$ denotes that an increment in variable $\mathrm{X}$ implies an immediate increment in variable Y. A dashed black arrow implies that the positive influence is not immediate, but is delayed by one time step. A solid grey arrow from $\mathrm{X}$ to $\mathrm{Y}$ denotes an immediate negative influence, i.e. that an increment in variable $\mathrm{X}$ implies an immediate decrement in variable $\mathrm{Y}$ 
market share. Therefore, its profits and R\&D investment will also increase. This will allow it to improve its product performance at a greater speed. Besides this, as firms gain more market share, they will also set higher prices which, in turn, will make them lose competitiveness and growth capacity. Likewise, an increase in spending on R\&D increases unit costs which will also increase their prices and reduce competitiveness and, consequently, their capacity to grow. Furthermore, as a firm improves its performance, it will tend to approach the maximum performance level at any given time, and so the possibilities of improvement here may also be reduced. The lower part of Fig. 1 shows the mechanism for strategic learning, with which firms determine the higher or lower intensity of their R\&D investment.

Finally, the mechanism of a firm's entry introduces new issues into the scheme in Fig. 1. New innovative entrants appear on the scene contributing to reshape the sectorial structure. The probability of these entrants appearing is higher, the greater the maximum profit rate; and lower, the higher the entry barriers.

Let us note that, in this scheme, there are six parameters playing a central role, i.e.: the price-performance sensitivity of demand $\alpha$; the two parameters of $R \& D$ strategic updating $\beta, \sigma$; parameter $u_{\text {Max }}$ giving the level of technological opportunities in the sector; parameter $\phi$ which offers an idea of the barriers to imitation; and parameter $\lambda$ which captures the entry barriers in the industry. ${ }^{10}$

It is worth noting that much of the heterogeneity and dynamic richness of this model comes from its stochastic components. To illustrate this point, let us focus on the deterministic version of the model, where $u_{\mathrm{Max}}=\sigma=0$ and $\lambda=1$. It can be proved (see Appendix 1) that the only stationary ${ }^{11}$ situations in such a deterministic model are those where all firms present in the market become indistinguishable from each other. This does not mean that all firms in a model run will necessarily converge to the same characteristics; some of them may perish on the way. What it means is that a necessary (and sufficient) condition for stationarity is that all surviving firms end up sharing the market equally, by selling an identical product (i.e. with the same performance) at exactly the same price.

Such a deterministic and familiar state of affairs contrasts with the results obtained when stochastic innovation is possible and new firms can enter the market. In such a case, the market never settles: firms enter and exit the market, and small firms can make dramatic innovations that allow them to rise above their competitors. Under certain conditions, these innovative firms may even challenge the market leader, and make it fall. Depending on various factors, leaderships may last for only a few time periods, or they may continue for a long time; the market may be dominated by only a few consolidated firms, or it may be shared among many small firms. In such stochastic settings, even though there is a constant turnover of firms, neat dynamic patterns emerge, which have clearly defined properties that depend on the particular parameterisation of the model.

\footnotetext{
${ }^{10}$ Let us point out the importance of differentiating between barriers to imitation and technical entry barriers. Thus, (e.g.) in the aircraft-engine industry we find high technical entry barriers, together with low barriers to imitation (Marsili 1999).

${ }^{11}$ Our concept of stationarity implies that $s_{i t}=s_{i t+1}$ and $r_{i t}=r_{i t+1}$, for all $i=1, \ldots, n$ and for all $t$.
} 
Table 1 Parametric values for computational analysis

\begin{tabular}{llll}
\hline$\alpha$ & 0.1 & 0.5 & 0.9 \\
$\lambda$ & 0.1 & 0.5 & 0.9 \\
$\mathrm{u}_{\text {Max }}$ & 0.1 & 0.5 & 0.9 \\
$\phi$ & 0.1 & 0.5 & 0.9 \\
$\beta$ & 0.1 & 0.5 & 0.9 \\
$\sigma$ & 0.1 & 0.3 & \\
\hline
\end{tabular}

Due to the complexity and stochastic nature of the model, we cannot offer closedform solutions for the properties of the observed dynamic patterns, but we can approximate them with confidence and rigour using extensive computer simulations. All the simulation runs reported in this paper can be replicated using the applet provided in the supplementary material (see http://luis.izqui.org/models/indyterrod/).

In Table 1, we present the parametric values we will combine. ${ }^{12}$

Thus, we explore 486 different parametric settings. Parameter $K^{\text {maxEntry }}$ turned out not to be particularly significant within a sensitive range, so we fixed its value at 0.05 . For each combination of the parameter values shown in Table 1, we ran 1,000 simulations until time step 30,000, and compiled various statistics (such as the Herfindhal index and the number of firms) at the end of each simulation run. Thus, the analysis presented below summarises a total of 486,000 simulation runs. Naturally, our hope is that the sample distributions of the statistics observed at time 30,000 are representative of the general dynamics of the model for each parameter setting. To make sure this is the case, we compared the sample distributions observed at time 30,000 with those observed at time 20,000. In all cases, the difference between these two sample distributions was not significant in the context of our study, so we are reasonably confident that all the values reported in this paper are representative of the general dynamics of the system.

As for initial conditions, the initial number of firms $n_{0}$ and the initial performance level $x_{0}$ were both set to a value of one; and the initial ratio of R\&D over profits was $r_{0}=0.3$. We are confident that the effect of these initial conditions on the results reported in this paper is minimal, since the distributions of each of these variables $\left(n_{t}, r_{t}\right.$ and $\left.x_{t}\right)$ at times 20,000 and 30,000 were similar, and different from the initial conditions, for all parameterisations. ${ }^{13}$

In this way, we obtain simulation outputs in the form of series of relevant variables for the analysis of the structure and evolution of our modelled industry (i.e. number of firms; index of industrial concentration; entry/exit pattern; etc). In the next Section we present the results obtained through simulations.

\footnotetext{
${ }^{12}$ Let us remember that throughout our work, in general, we will suppose high cumulativeness in Eq. 10, that is, $\eta=1$.

${ }^{13}$ All our simulation results can be replicated using the applet provided at: http://luis.izqui.org/models/ indyterrod. By running this applet, the reader can easily check that the stationary distributions we report in this paper emerge regardless of the initial conditions. That is, neat patterns for the limiting distributions emerge, which depend on the specific parametric settings, but not on the departure point.
} 


\section{Industry dynamics, demand and technological regimes}

The analysis of our results shows the special relevance of parameter $\alpha$ (the priceperformance sensitivity of demand) for the dynamics and structure of the sector. As we will analyze in the following two sections (Sections 4.1 and 4.2), we can state that, although with demand conditions where consumers value price and performance similarly $(\alpha=0.5)$, the model reproduces the expected relationships between technological regimes and patterns of industry transformation (see Table 2 and Section 4.1), it can be affirmed that, as a general property of the model, these relationships are strongly conditioned by the demand profile (see Figs. 8 and 9). Hence, in different technological regimes, a high performance sensitivity of demand $(\alpha=0.1)$ tends to concentrate the market, whilst high values of $\alpha(\alpha=0.9$; i.e. high price sensitivity of demand) fragment the market (see Section 4.2).

Consequently, we can find that, for example, drawing on the classical Winter (1984) distinction between entrepreneurial vs routinized regimes, in an entrepreneurial regime (see Table 2 for specification), if the demand is very sensitive to performance, the pattern of creative destruction fades, with certain features of creative accumulation appearing (e.g. high market concentration). In the same way, in a routinized regime, if the price sensitivity of the demand is high, certain features of creative accumulation disappear and new patterns-more typical of creative destruction- emerge.

In the next two sections, we analyze in detail the role of demand in industrial dynamics. We first focus on intermediate demand profiles $(\alpha=0.5$; Section 4.1) and afterwards we explore the case of extreme values for the price-performance sensitivity of demand $(\alpha=0.1 ; \alpha=0.9$; Section 4.2).

\subsection{Intermediate values for the price-performance sensitivity of demand}

Let us consider that the price-performance sensitivity of demand adopts an intermediate value (i.e. $\alpha=0.5$ ). Given this value of $\alpha$, we will analyze the relationships between distinct parametric configurations-characterizing alternative technological regimes - and alternative patterns of industrial transformation. In accordance with the

Table 2 Technological regimes and industry evolution

\begin{tabular}{lc}
\hline Technological regime (setting) & Pattern of industry evolution \\
\hline Routinized & Creative accumulation \\
High/Low technological opportunities & Few firms \\
High entry barriers & High market concentration \\
High appropriability (e.g. Computer Mainframes) & Low entry rate \\
Entrepreneurial & Creative destruction \\
High/Low technological opportunities & Many firms \\
Low entry barriers & Low market concentration \\
Low appropriability (e.g. Biotechnology) & High entry rate \\
\hline
\end{tabular}


definition of technological regime, we characterize the different regimes in terms of three parameters: $u_{\text {Max }}$ (level of technological opportunities), $\lambda$ (entry barriers) and $\phi$ (barriers to imitation). We will assume_-as an almost permanent assumption- high cumulativeness in Eq. 9, that is, $\eta=1$. Relaxing this assumption leaves extensions for future research (see Appendix 2).

Now, let us recall that, traditionally, we have seen two different basic types of technological regimes in the literature (see Winter 1984): the entrepreneurial regime, leading to creative destruction patterns of industry evolution; and the routinized regime, which generates creative accumulation dynamics. In Table 2, we summarize the characteristic features of these two basic types.

Observing Table 2, it is interesting to test whether our model can reproduce the habitual relationships with intermediate demand conditions $(\alpha=0.5)$. We shall see that this is indeed the case.

\subsubsection{Routinized technological regime}

As indicated by Winter (1984), a routinized regime is one that favours innovation by established firms. Thus, we set up a parametric scenario which represents the difficulty to enter into the sector due to high entry barriers. In addition, here knowledge is hardly shared internally (strong appropriability conditions). We reproduce these conditions in our model by making $\lambda=0.9, \phi=0.1$.

Regarding the level of technological opportunities, we shall begin with an intermediate level. Later on, we shall vary the value of $u_{\text {Max }}$ and confirm that the higher the level of technological opportunities, the clearer the differences between the dynamics emerging from routinized vs entrepreneurial regimes are. Finally, we point out that the assumption of high cumulativeness $(\eta=1)$ strengthens the routinized character of the regime we will simulate.

Thus, as our starting point, the parametric scenario for our simulations corresponds to:

$$
\alpha=0.5 ; \lambda=0.9 ; \phi=0.1 ; u_{\operatorname{Max}}=0.5 ; \beta=\{0.1,0.5,0.9\} ; \sigma=\{0.1,0.3\} .
$$

The values of the Herfindhal index and the number of firms at $t=30,000$, obtained for the different parametric configurations of the routinized regime, appear in Fig. 2.

Creative accumulation In these conditions, the emergent structure of the sector is highly concentrated (average Herfindhal Index around 0.72) and tends to stabilize around a small number of firms (about 4 ). These features are peculiar to a creative accumulation pattern (see Table 2).

If we explore the processes underlying the emergence of the results in Fig. 2, we can see ${ }^{14}$ that the evolution in the sector can be described as a succession of eras of firms, each one with a structure of the "oligopoly with a dominant firm" kind; and the dominant firm changes with time.

\footnotetext{
${ }^{14}$ These processes can be reproduced by using the applet: http://luis.izqui.org/models/indyterrod.
} 


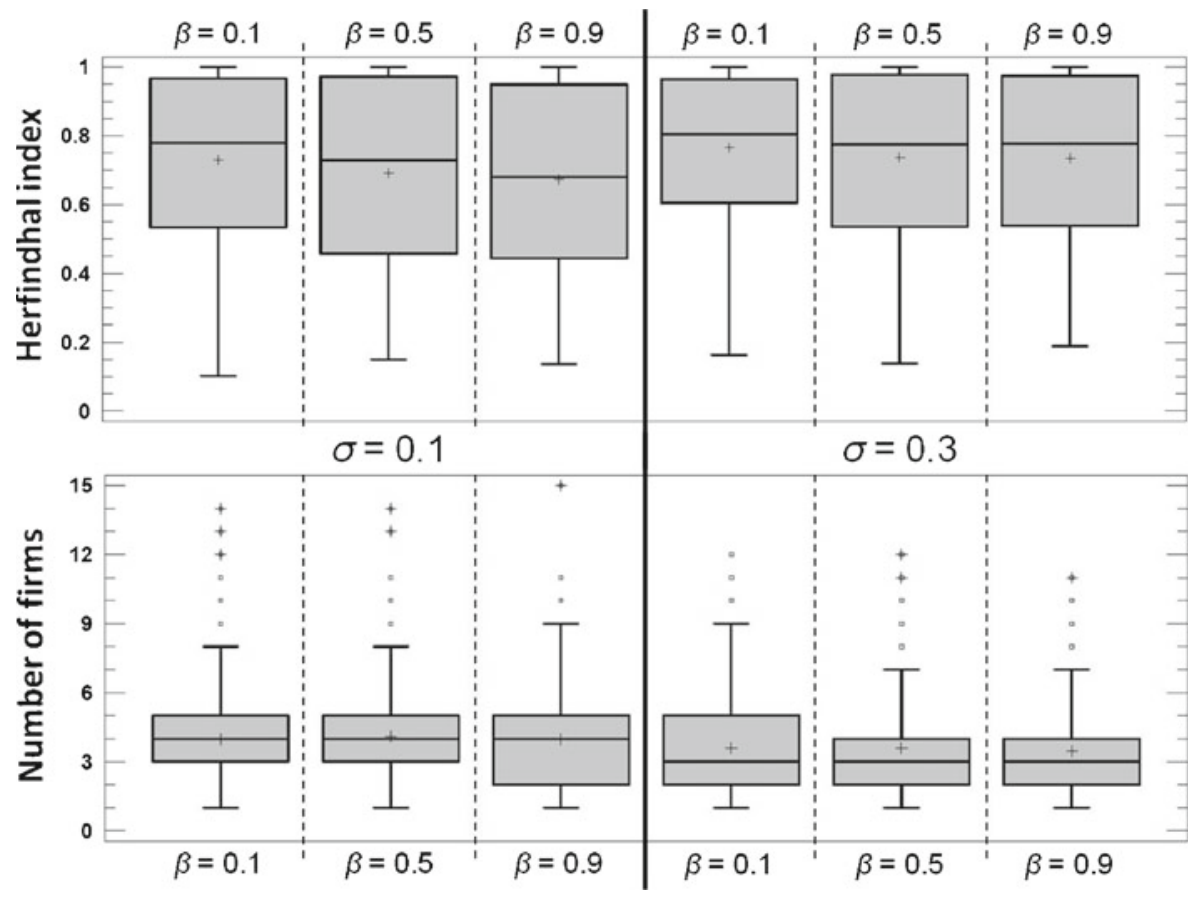

Fig. 2 Box-plots of the Herfindhal index (above) and the number of firms (below) at time step 30,000, for $\alpha=0.5, \lambda=0.9, \phi=0.1, u_{\mathrm{Max}}=0.5$, and different values of $\sigma$ and $\beta$. Each box-plot represents data from 1,000 simulation runs

In these processes (typical of creative accumulation), for long periods of time, a firm which survives much longer than the others will become market leader with a high market share (the average market share of the leader is greater than 0.8 (s.d. $<0.003)$ ); it is also leader in product performance (the average relative performance of the leader $\left(x_{\text {leader }} / x^{\mathrm{Max}}\right)$ is greater than 0.998 (s.d. $\left.<0.001\right)$ ). During each era, the corresponding leader is continually challenged by new entrants which survive for a while. On average, each dominant firm co-exists alongside 3 or 4 smaller ones (see Fig. 2).

Clearly, the leaders enjoy certain competitive advantages. One such advantage is a greater market share, which allows them to invest more in R\&D-Eq. 7—and develop their products more quickly. The advantage in performance has two positive effects: firstly, it creates a favorable situation for the leader to capture market share-Eq. 5; in addition, it reinforces the accumulative innovation process-Eq. 10. Regarding prices, the greater mark-up applied by the leader increases its price (Eqs. 1 and 9). Leadership will be maintained while the combination of performance and prices offers sufficient competitiveness to the leader-Eq. 3 .

It is worth pointing out that being the leader has its drawbacks. A highly concentrated market generates a high maximum profit rate, which attracts new potential entrants (Eqs. 2 and 11). The visibility (high market share) of the leader causes many of the entrants to copy its performance. Although most of these entrants do not 
manage to maintain their relative performance, entrants occasionally appear with such a combination of price and performance that they can stay in the market. Sometimes, but not often, some of these entrants may overtake the leader and start a new era. In Fig. 3, we show the number of leadership shifts during a certain simulation interval (for 10,000 periods of time).

According to Fig. 3, when $\beta$ is low, the era shifts are much less common. Additionally, we will see later that the number of leadership shifts is lower in the routinized regime than in the entrepreneurial regime. Once again, this result is expected in a creative accumulation pattern of change.

We show in Fig. 4 how the results change when modifying the level of technological opportunities:

Figure 4 shows that the higher the level of technological opportunities, the higher the degree of concentration in the sector tends to be. The effects of $u_{\text {Max }}$ indicate that, under conditions of a routinized regime, a high level of technological opportunities reinforces the pattern of creative accumulation. Likewise, as we shall see below, it is interesting to compare Figs. 4 and 7 (below); this comparison shows that the higher the value of $u_{\mathrm{Max}}$, the clearer the difference between the concentration levels emerging from routinized versus entrepreneurial regimes.

To summarize, we can state that under the conditions typical of routinized regimes, and considering an intermediate value of the price-performance sensitivity of demand, we have found the expected patterns of creative accumulation. This emphasizes the plausibility of our model.

\subsubsection{Entrepreneurial technological regime}

Entrepreneurial regimes are characterized by open and permeable learning conditions favouring the emergence of new innovative firms. Therefore, now, we set up a parametric scenario in which it is easy to enter because of the low entry barriers, and knowledge is spread easily (weak appropriability conditions). Likewise, the level of

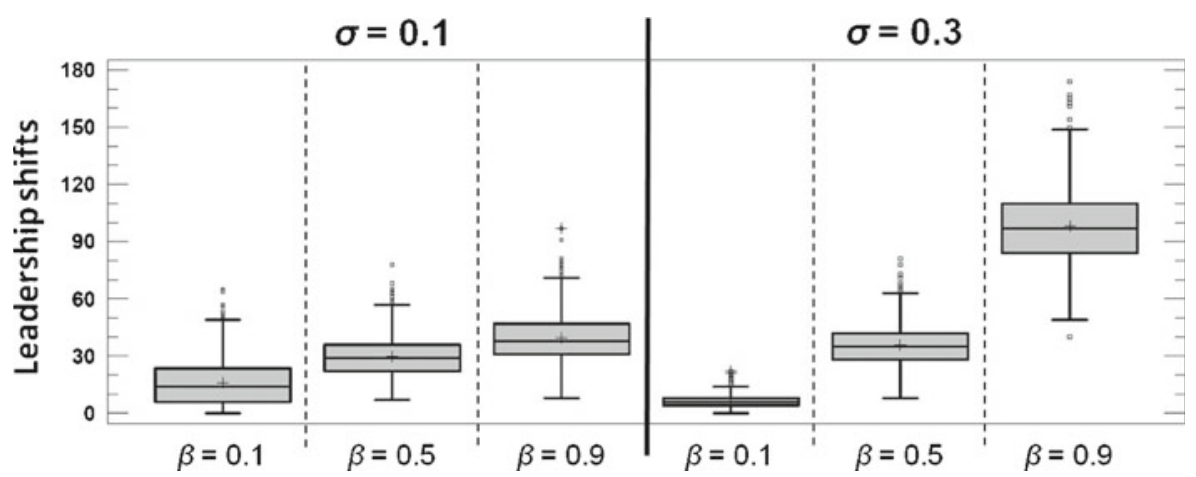

Fig. 3 Box-plots of the number of leadership shifts between time step 20,001 and time step 30,000, for $\alpha=0.5, \lambda=0.9, \phi=0.1, u_{\mathrm{Max}}=0.5$, and different values of $\sigma$ and $\beta$. Each box-plot represents data from 1,000 simulation runs 


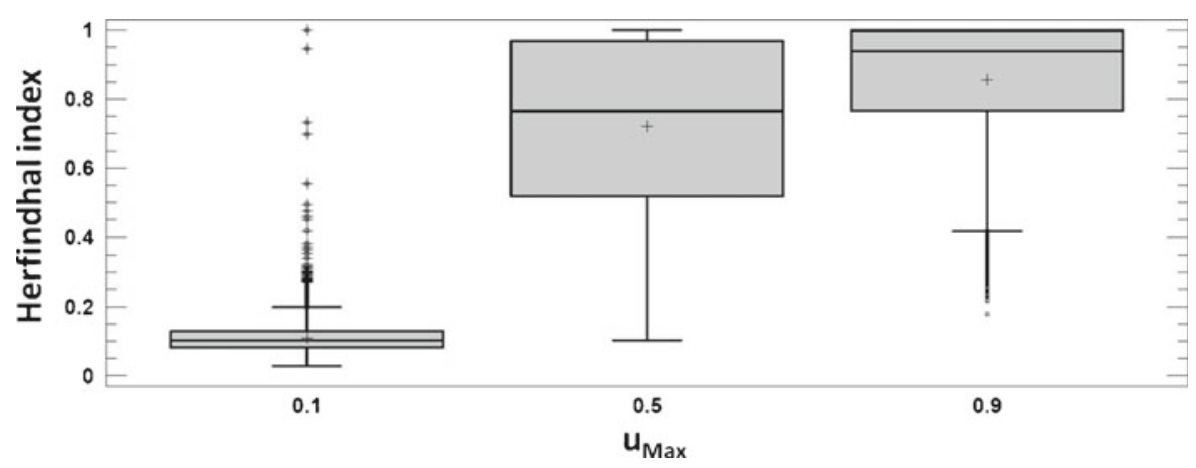

Fig. 4 Box-plots of the Herfindhal index at time step 30,000 for $\alpha=0.5, \lambda=0.9, \phi=0.1$ and different values of $u_{\mathrm{Max}}$. Each box-plot represents data from 6,000 simulation runs (1,000 runs for each combination of values of $\beta=\{0.1,0.5,0.9\}$ and $\sigma=\{0.1,0.3\}$ )

technological opportunities can be wider or narrower. As we will see, under conditions of high technological opportunities, the levels of market concentration emerging from this regime will differ in a stronger way from the ones in the routinized regime. In addition, although for coherence and due to the space limitations, we run the model in high cumulativeness conditions $(\eta=1)$, we present in Appendix 2 the results for entrepreneurial regimes with low cumulativeness $(\eta=0.1){ }^{15}$

We shall start by considering the parametric scenario for our simulations:

$$
\alpha=0.5 ; \lambda=0.1 ; \phi=0.9 ; u_{\operatorname{Max}}=0.5 ; \beta=\{0.1,0.5,0.9\} ; \sigma=\{0.1,0.3\}
$$

The values of the Herfindhal index and the number of firms at $t=30,000$, obtained for different parametric configurations of the entrepreneurial regime, appear in Fig. 5.

Creative destruction Under these conditions the emergent structure of the sector is not concentrated (average Herfindhal Index around 0.1) and tends to stabilize around a large number of firms. These features are representative of a creative destruction pattern (see Table 2).

The industrial dynamics ${ }^{16}$ can also be described as a succession of eras of firms, each one with a "dominant firm" structure, where the dominant firm can change over time. However, in contrast to the routinized regime, the structure of the sector is not concentrated, and so the leader has a market share only slightly higher than that of the others. The average market share of the leader is below 0.2 (s.d. $<0.001$ ), whilst its average relative performance $\left(x_{\text {leader }} / x^{\mathrm{Max}}\right)$ is greater than 0.999 (s.d. $\left.<0.0001\right)$ ).

Owing to the high level of openness in the sector, the leader is continually threatened by new entrants-many more than those in the routinized regime. These new

\footnotetext{
${ }^{15}$ The results of Appendix 2 show that, regarding low cumulativeness, the creative destruction character holds perfectly in the dynamics. With a provisional rough approximation, we can see that the cumulativeness parameter does not seem to have an excessive effect on the limit results in this case (see Appendix 2 and Fig. 5). However, future research should offer an exhaustive analysis of the role of cumulativeness in the model.

${ }^{16}$ See applet in: http://luis.izqui.org/models/indyterrod.
} 


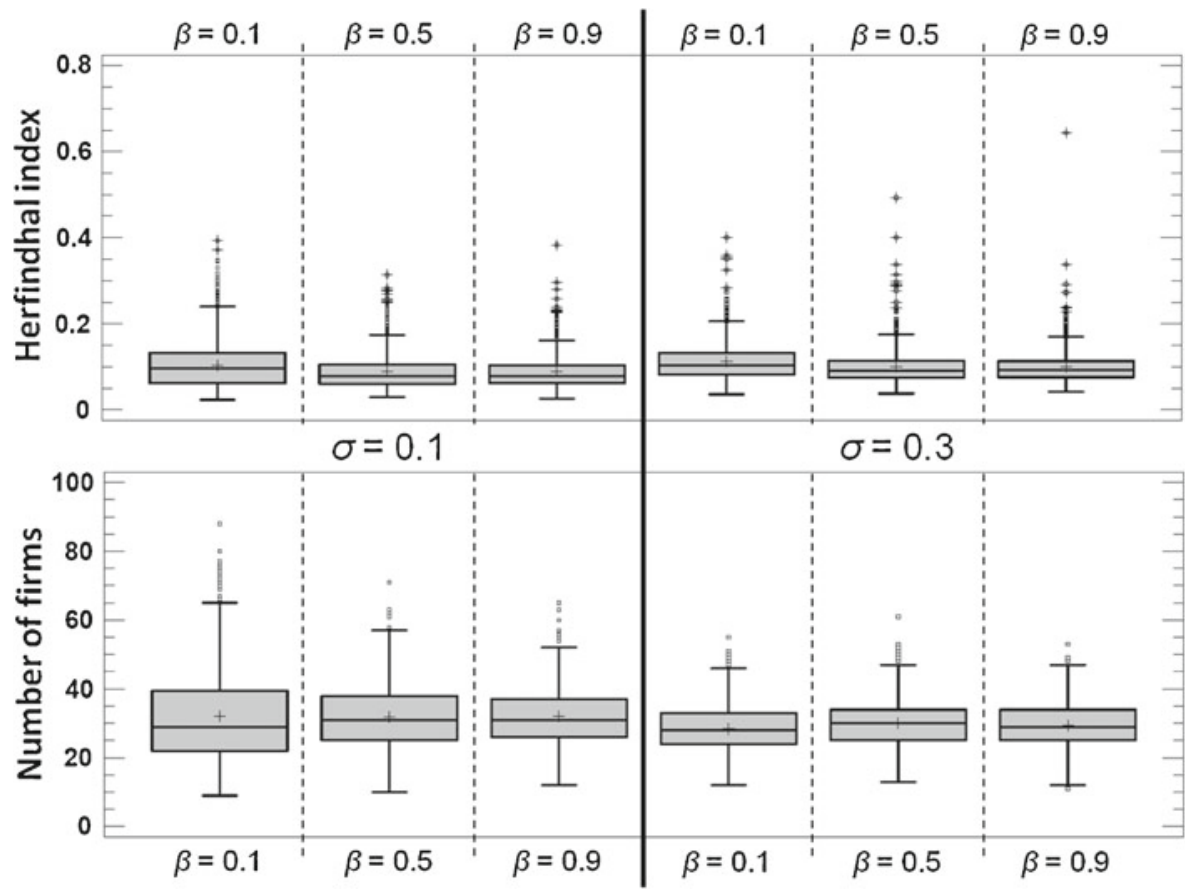

Fig. 5 Box-plots of the Herfindhal index (above) and the number of firms (below) at time step 30,000, for $\alpha=0.5, \lambda=0.1, \phi=0.9, u_{\mathrm{Max}}=0.5$, and different values of $\sigma$ and $\beta$. Each box-plot represents data from 1,000 simulation runs

entrants reach a performance relatively close to that of the leader, and fix lower prices owing to their smaller size. The combination of both factors explains that, in the entrepreneurial regime, the leader loses a lot of market share to the new entrants.

The relatively homogeneous character of market shares in this regime, together with low entry barriers and the low appropriability of innovations, generate a pattern of industry evolution which is more turbulent than that observed in routinized conditions. Hence, many firms enter, challenge and imitate each other with relative ease, while knowledge is widely spread and shared, homogenizing performances.

All these effects are reflected in the fact that, in the entrepreneurial regime, the number of leadership shifts is higher than in the routinized regime (compare Figs. 3 and 6). It is also interesting to see that high values of both, $\beta$ and $\sigma$, increase the number of leadership shifts (see Fig. 6).

We shall now analyze how the results are altered when the level of technological opportunities is modified $\left(u_{\mathrm{Max}}=\{0.1,0.5,0.9\}\right)$.

From Fig. 7, when opportunities are limited $\left(u_{\mathrm{Max}}=0.1\right)$, the sector becomes very fragmented and significantly dispersed. On the other hand, when the level of technological opportunities in the sector is high $u_{\text {Max }}=0.9$, the concentration in the sector tends to increase, but never reaches high levels of industrial concentration.

It is noteworthy that, in a context of high technological opportunities (high value of $u_{\mathrm{Max}}$ ), the differences in market concentration between the entrepreneurial regime 


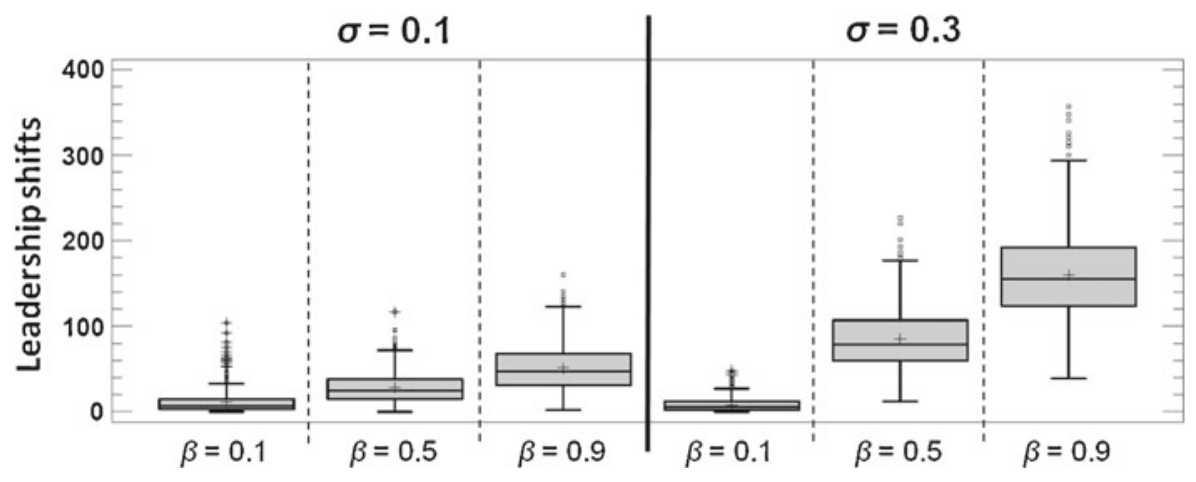

Fig. 6 Box-plots of the number of leadership shifts between time step 20,001 and time step 30,000, for $\alpha=0.5, \lambda=0.1, \phi=0.9, u_{\mathrm{Max}}=0.5$, and different values of $\sigma$ and $\beta$. Each box-plot represents data from 1,000 simulation runs

and the routinized regime are much clearer (compare Fig. 7 with Fig. 4). Thus, as $u_{\text {Max }}$ grows, the differences (in terms of the Herfindhal index) between the industry structures emerging from the routinized vs entrepreneurial conditions become greater.

To sum up, we can state that our model generates the standard results in the literature when the price-performance sensitivity of demand takes its intermediate level. We obtained creative accumulation patterns emerging from routinized regimes, and creative destruction emerging from the entrepreneurial regimes. Nevertheless, as we will see in Section 4.2, the standard results seem to fade under biased demand profiles, with new results appearing. Therefore, we could affirm that the well-known results in the literature only emerge under certain demand conditions in our model. To see this, we study the case of $\alpha=0.1$ y $\alpha=0.9$ in Section 4.2.

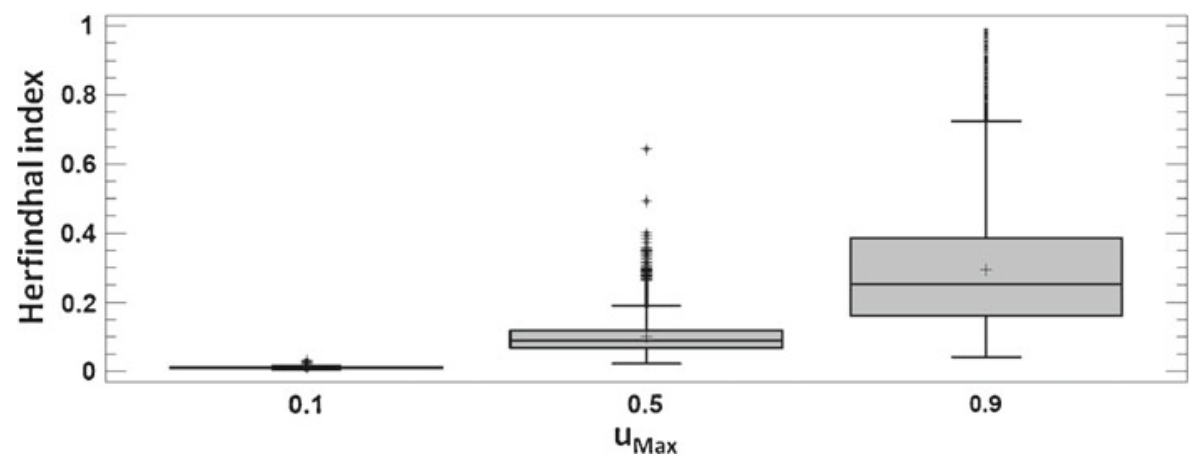

Fig. 7 Box-plots of the Herfindhal index at time step 30,000 for $\alpha=0.5, \lambda=0.1, \phi=0.9$ and different values of $u_{\text {Max }}$. Each box-plot represents data from 6,000 simulation runs (1,000 runs for each combination of values of $\beta=\{0.1,0.5,0.9\}$ and $\sigma=\{0.1,0.3\})$ 


\subsection{Extreme values for the price-performance sensitivity of demand}

In this section, we show that the role of demand is crucial in explaining the sectorial dynamics. To be specific, we find that if consumers value product performance highly, $\alpha=0.1$, the sector tends to become concentrated; on the contrary, if consumers are highly price-sensitive, $\alpha=0.9$, then the sector tends to atomize (see Figs. 8 and 9). This is so, no matter which technological regime we are in. To be specific, as can be seen in Figs. 8 and 9, for $\alpha=0.1$, the average Herfindhal index for most parametric configurations is greater than 0.75 , and the number of firms is below 10. Likewise, for $\alpha=0.9$, the average Herfindhal index for most parametric settings is close to " 0 " (almost perfect competition) and, in general, over 70 firms survive.

Taking into account the mechanisms of the model seen in Fig. 1, we shall try to interpret these results. We begin by asking why a high performance sensitivity of

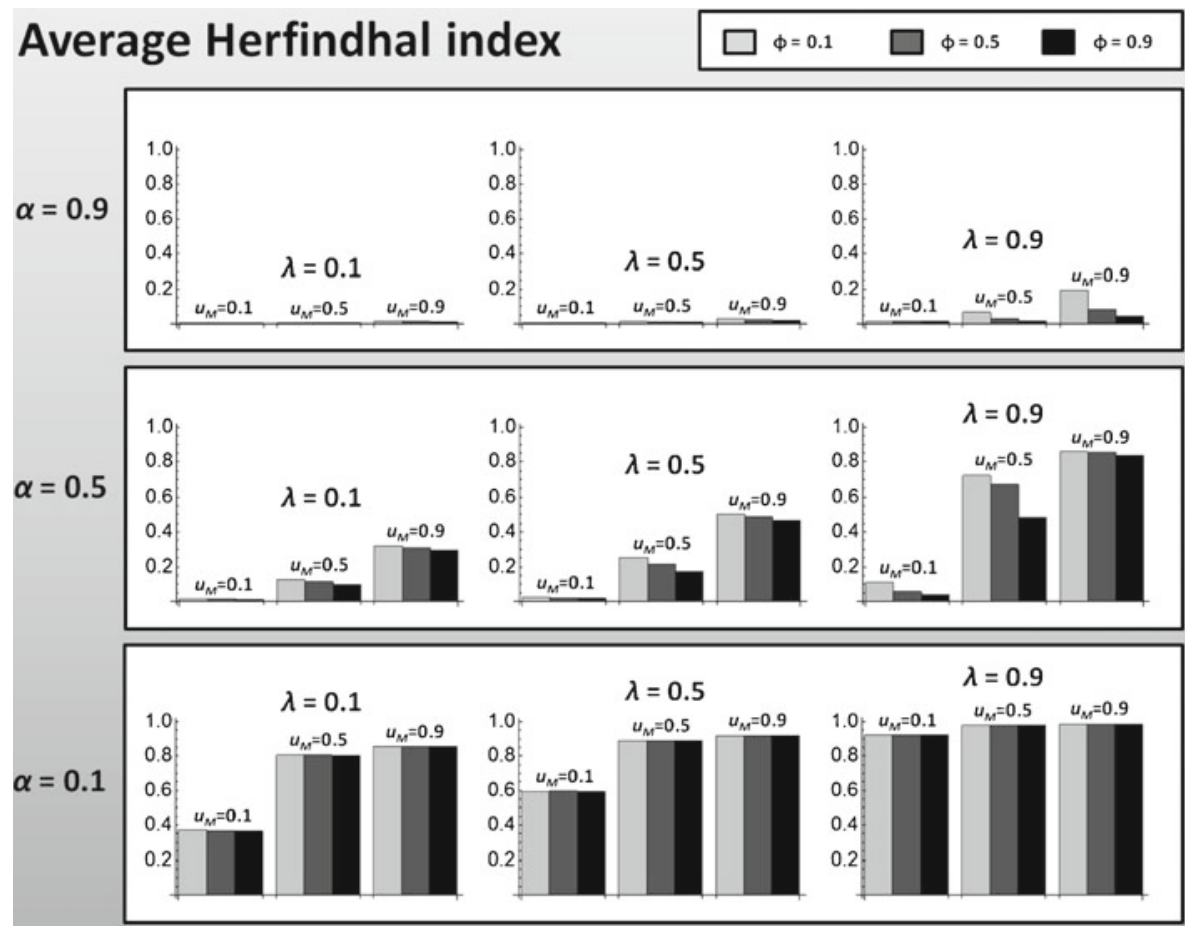

Fig. 8 Average Herfindhal index at time step 30,000, for different values of $\alpha, \lambda, u_{\mathrm{Max}}$, and $\phi$ (these are the four parameters that explain the greatest amount of variability in the Herfindhal index (the selection of the 4 most explanatory parameters (out of the 6 considered) has been carried out comparing the 15 different ANOVA models of 4 parameters and all their interactions. The model including $\alpha, \lambda, u_{\mathrm{Max}}, \phi$ and their interactions was the model with the lowest sum of squared errors. Incidentally, all factors and their interactions are significant at 0.0001 in this model, but care must be taken when interpreting this result, since the assumption of normality does not hold here.)). Thus, each bar represents the average Herfindhal index at time step 30,000 calculated over 6,000 simulation runs (1,000 runs for each combination of values of $\beta=\{0.1,0.5,0.9\}$ and $\sigma=\{0.1,0.3\})$. All standard errors are below 0.005 


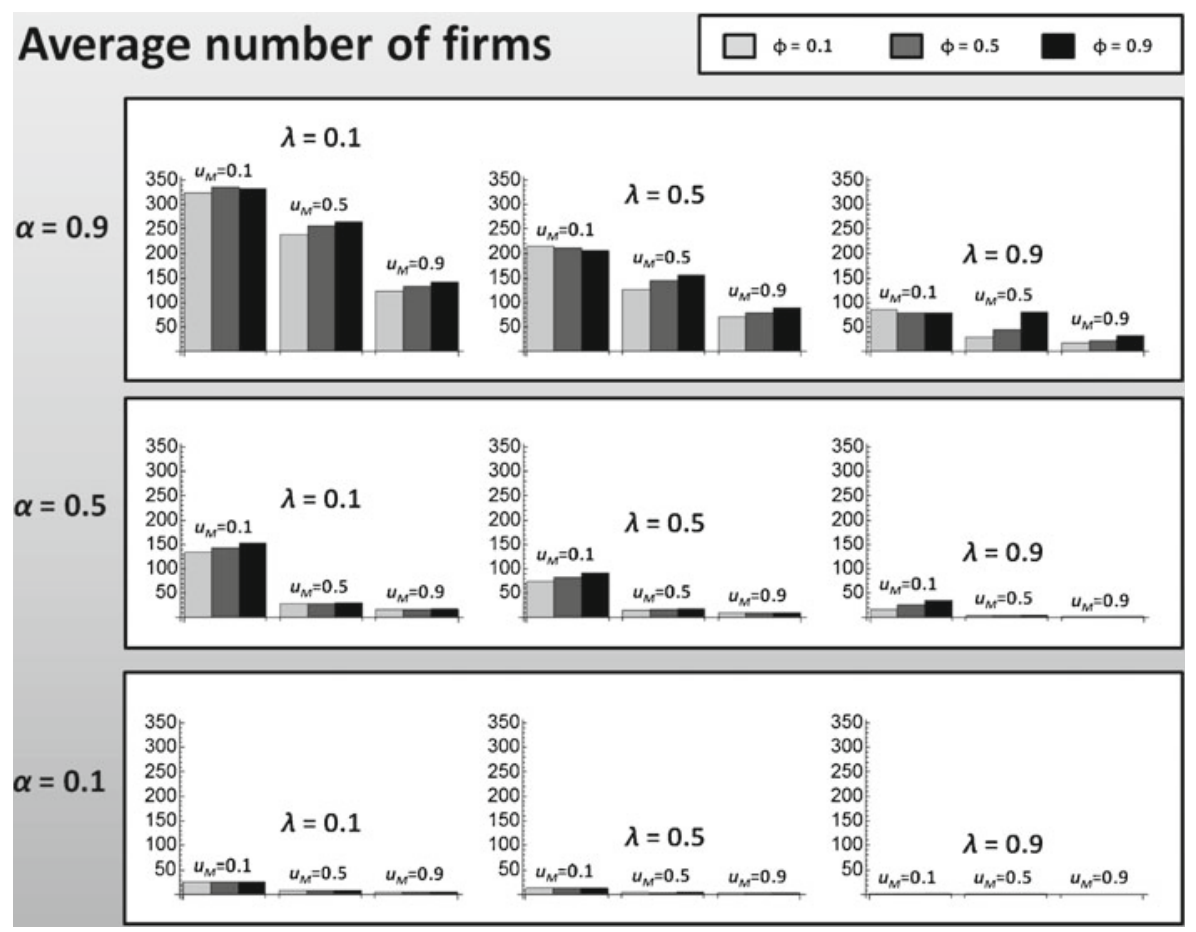

Fig. 9 Average number of firms at time step 30,000, for different values of $\alpha, \lambda$, $u_{\mathrm{Max}}$, and $\phi$. Thus, each bar represents the average number of firms at time step 30,000 calculated over 6,000 simulation runs ( 1,000 runs for each combination of values of $\beta=\{0.1,0.5,0.9\}$ and $\sigma=\{0.1,0.3\})$. All standard errors are below 1

demand (low $\alpha$ ) leads, in most cases, to a high concentration of the sector. To understand this, the extreme case $\left\{\alpha=0.1, \lambda=0.9, u_{\text {Max }}=0.9\right\}$ is particularly useful—see Figs. 8 and 9-, a parameterization shared by 18,000 simulation runs in our study. As we can see, the Herfindhal index tends to be very close to 1, with only one surviving firm in most cases. In fact, it can be shown that in the 18,000 simulation runs, the founding firm of the sector always survives and dominates the market. This is so because this firm enjoys certain competitive advantages which make it unbeatable in an environment where demand places a high value on product performance level (i.e. $\alpha=0.1$ ). Thus, a first advantage is its higher market share (which is 1 in the initial period), allowing it to invest more in $\mathrm{R} \& \mathrm{D}-\mathrm{Eq}$. 7-and develop its product performance more quickly. The advantage in performance has two positive effects: on the one hand, it enables the leader to capture and maintain a higher market share-Eq. 5; on the other hand, it reinforces the accumulative process of innovation-Eq. 10-, which is an advantage due to the high level of technological opportunities $\left(u_{\mathrm{Max}}=\right.$ 0.9). Although other firms enter, attracted by the high profit rate of the sectorEq. 11-, they do not manage to seize the leadership position from the founder.

This all happens in the extreme case $\left\{\alpha=0.1, \lambda=0.9, u_{\mathrm{Max}}=0.9\right\}$. However, it is a very generalized result. It is worth pointing out that as entry barriers diminish and/or 
the level of technological opportunities is reduced, the advantage of the founding firm is eroded, and the level of concentration in the sector is reduced (see Figs. 8 and 9). However, the levels of industrial concentration are, in general, very high — and the number of firms, low. ${ }^{17}$

Now, let us look at the effects of considering demand to be extremely sensitive to price (i.e. $\alpha=0.9$ ). In this case, as seen in Figs. 8 and 9, the dynamics of the sector lead to a high degree of fragmentation, and the average number of firms is high. In fact, except for $\lambda=0.9$ and $u_{\text {Max }}=0.9$, the average Herfindhal index is below 0.1 (and in most cases below 0.05), and the average number of firms is, in general, higher than 50 (in some cases this figure can be over 300).

Once again, to understand the mechanism underlying these results, we consider the scheme in Fig. 1 again and focus on the extreme case $\left\{\alpha=0.9, \lambda=0.1, u_{\text {Max }}=\right.$ 0.1 . Both Figs. 8 and 9 show that, for this case, the average Herfindhal index is close to zero (almost perfect competition) and, on average, over 300 firms survive.

In this scenario, the firm founding the sector quickly finds itself threatened by new entrants which, with their small size, set low prices and possess a performance level close to the maximum at that time-Eq. 11. In a context in which consumers are very sensitive to price, new entrants wear away the market share of the leading firmEq. 3. Likewise, the low level of technological opportunities $\left(u_{\operatorname{Max}}=0.1\right)$ favors the homogenization of the sector-Eq. 10-, and even more so, the lower the barriers to imitation (high values of $\phi$ ). The final result is a high degree of fragmentation of the sector with firms offering products which are more similar, the lower the degree of appropriability of the sector. Once again, the extreme case helps us to understand how the model works, but the result of low concentration when demand is highly price-sensitive is a general one (see Fig. 8).

All the aforementioned, leads us to reflect on the importance of considering demand aspects in the analysis of industrial dynamics, as previously pointed out by Malerba (2006) and others. Malerba states that, at least in the Schumpeterian tradition, demand has been considered a rather marginal aspect, with the supply side being emphasized instead. Joseph A. Schumpeter himself might have been responsible for this, given his consideration of users as passive agents in the innovation process. Our results seem to confirm Malerba's concerns: once demand moves to the forefront (as in our model), not only do new results appear but we also find that the known results can be looked at from a new perspective.

\section{Concluding remarks}

We were persuaded to begin this work by the almost generalized feeling that, after three decades of advances in the study of industrial dynamics, it might be

\footnotetext{
${ }^{17}$ Although the level of concentration decreases for the case of very low technological opportunities and very low entry barriers, we should ask ourselves whether it is realistic to consider a sector which innovates very little in product and where demand is very performance sensitive. This special case is probably the least relevant one from an empirical point of view.
} 
time to explore the interplay between the well-studied knowledge-related aspects of innovation, and certain demand-driven mechanisms underlying market competition. The increasing number of contributions that have appeared during the last decade, expressing the need to examine the interactions between innovation and demand, seem to support this idea. With the aim of contributing to this body of works, we have proposed an evolutionary model of industrial dynamics capable of analyzing market transformations and concentration in different demand conditions and in alternative technological regimes.

The complexity of the subject, together with the variants in formulation and analysis posed by our model, leads us to present our model as a first step in a more general research strategy which will be extended with time. However, our results already seem to confirm that demand can play a decisive role in industrial dynamics. From the computational analysis of our model we have found that, although for intermediate values of the price-performance sensitivity of demand the well-known relationships between technological regimes and industry evolution generally hold, this is not the case when we consider biased demand profiles - whether they be biased towards price or to performance. Hence, in our model, a high price sensitivity of demand tends to atomize the industry, no matter the technological regime we are in. Likewise, when the demand is clearly performance-sensitive, market concentration emerges in remarkably different technological conditions. This result is undoubtedly worthy of deeper study at a later date. In fact, we have attempted to formulate as simple a model as possible, in order for our results to be easily understandable and to show the way for future generalisations. In this sense, we shall finish our work by laying down lines of work which, in our opinion, follow on from our fundamental results.

On the one hand, the fact that our results reproduce-under certain conditionsthe expected relationships between certain technological regimes and corresponding patterns of industrial transformation allows us to be confident about the plausibility of our model. Hence, as in previous theoretical and empirical contributions (Winter 1984; Breschi et al. 2000), we have found that, for intermediate demand profiles, typical entrepreneurial settings generate creative destruction patterns of change, while the alternative routinized configurations engender creative accumulation. On the other hand, the most interesting lines of future research derive from the fact that, in our model, somewhat surprisingly, the predictable processes of creative destruction and creative accumulation fade as the price-performace sensitivity of demand varies. To be specific, we believe that there are at least three promising lines which would allow for a deeper look at these results. Hence:

Firstly, a more exhaustive analysis of the roles of cognitive and R\&D cumulativeness in the model may be enlightening. The formal and computational complexities linked to this possible extension of our work are beyond the limited scope of a single paper. However, we have already pointed out how this research could start out from the generalizations following on from Eq. 10.

Secondly, it would be interesting to explore the robustness of our results, considering alternative strategic learning routines, and different investment mechanisms. Once again, the complications involved in this theoretical generalization exceed the scope of our present work. 
Finally, we would like to point out that advances towards a more general formulation of our model would, perhaps, allow us to check the new results with more complex classifications of technological regimes. To this regard, the works by Marsili $(1999,2001)$ are an excellent departure point.

\section{Appendix 1}

Statement In the deterministic version of the model (i.e. $u_{\mathrm{Max}}=\sigma=0$ and $\lambda=$ 1), stationarity (i.e. $s_{i t}=s_{i t+1}$ and $r_{i t}=r_{i t+1}$, for all $i$ and for all $t$ ) implies that all firms present in the market end up becoming indistinguishable from each other. Specifically, using $n>1$ to denote the number of firms present in the market, in the long run (i.e. as time goes to infinity):

(a) $s_{i t}=s_{i}=1 / n, \forall i$.

(b) $r_{i t}=r_{i}=r, \forall i$.

(c) $c_{i t}=c_{i}=n /(n-r), \forall i$.

(d) $\quad p_{i t}=p_{i}=(n+1) /(n-r), \forall i$.

(e) $R_{i t}=R_{i}=r /(n(n-r)), \forall i$.

(f) $x_{i t}=x_{i}=x^{\mathrm{Max}}, \forall i$.

(The case where there is only one firm in the market is insignificant).

Proof The proof is conducted in several steps:

1. $r_{i t+1}=r_{i t}, \forall i, \forall t \Rightarrow\{$ Eq. 8$\} \Rightarrow r_{i t}=r, \forall i, \forall t$.

2. $s_{i t+1}=s_{i t}, \forall i, \forall t \Rightarrow\{\mathrm{Eq} .5\} \Rightarrow \gamma_{i t}=\bar{\gamma}_{t}, \forall i, \forall t$.

3. $c_{i t}=1+\frac{R_{i t}}{s_{i t}}=1+r_{i t-1} \pi_{i t-1} \frac{s_{i t-1}}{s_{i t}}=1+r_{i t-1} s_{i t-1} c_{i t-1} \frac{s_{i t-1}}{s_{i t}}=$ $\left\{s_{i t}=s_{i t-1}=s_{i} ; r_{i t}=r\right\}=1+r \cdot s_{i} \cdot c_{i t-1}$

Noting that $r \cdot s_{i}<1$, we can solve the recursive equation to obtain:

$$
c_{i t}=\left(1-\left(r \cdot s_{i}\right)^{t}\right) /\left(1-r \cdot s_{i}\right)+c_{i 0}\left(r \cdot s_{i}\right)^{t}
$$

Thus, taking limits when $t$ goes to infinity:

$$
\lim _{t \rightarrow \infty} c_{i t}=1 /\left(1-r \cdot s_{i}\right)=c_{i}
$$

4. $R_{i t+1}=r \cdot s_{i}^{2} \cdot c_{i t} \Rightarrow \lim _{t \rightarrow \infty} R_{i t}=r \cdot s_{i}^{2} /\left(1-r \cdot s_{i}\right)=R_{i}$.

5. $p_{i t}=\left(1+s_{i}\right) c_{i t} \Rightarrow \lim _{t \rightarrow \infty} p_{i t}=\left(1+s_{i}\right) /\left(1-r \cdot s_{i}\right)=p_{i}$.

Also, note that, for all $i$, the convergence of prices $p_{i t}$ to the corresponding limit $p_{i}$ is monotonous, and the series $\left|p_{i t}-p_{i}\right|$ is geometric and monotonously decreasing (remember that $r \cdot s_{i}<1$ ):

$$
\left|p_{i t}-p_{i}\right|=\left|\left(1+s_{i}\right)\left[c_{i 0}-1 /\left(1-r \cdot s_{i}\right)\right]\right|\left(r \cdot s_{i}\right)^{t}
$$


In simple words, prices stabilize, i.e. for any time $h$ :

$$
\left|p_{i h+1}-p_{i h}\right|>\left|p_{i t+1}-p_{i t}\right| \quad \forall t>h .
$$

6. $\gamma_{i t}=\bar{\gamma}_{t}, \quad \forall i, \forall t \Rightarrow \gamma_{i t}=\gamma_{j t}, \forall i, \forall j, \forall t$

Therefore:

$$
\begin{aligned}
\gamma_{i t}= & (1-\alpha) \frac{x_{i t}-\bar{x}_{t}}{\bar{x}_{t}}-\alpha \frac{p_{i t}-\bar{p}_{t}}{\bar{p}_{t}}=(1-\alpha) \frac{x_{j t}-\bar{x}_{t}}{\bar{x}_{t}}-\alpha \frac{p_{j t}-\bar{p}_{t}}{\bar{p}_{t}}=\gamma_{j t} \\
& (1-\alpha) \frac{x_{i t}-x_{j t}}{\bar{x}_{t}}=\alpha \frac{p_{i t}-p_{j t}}{\bar{p}_{t}} \\
& x_{i t}-x_{j t}=\bar{x}_{t} \frac{\alpha}{1-\alpha} \frac{p_{i t}-p_{j t}}{\bar{p}_{t}}
\end{aligned}
$$

Since $x_{i t}>0, \forall i, \forall t$, the equation above implies that beyond a certain time $T$ (i.e. when prices stabilize and there are no changes in the ranking of prices anymore-see point 5 of the proof) there cannot be changes in the ranking of performances either, i.e. $\exists T$ such that $x_{i T}>x_{j T} \Rightarrow x_{i t}>x_{j t}, \forall t>T$. Thus:

$\exists m, T$, such that $x_{m t}=x_{t}^{\mathrm{Max}}, \forall t>T$. Using Eq. 10, this implies that $x_{t}^{\mathrm{Max}}=$ $x^{\operatorname{Max}}, \forall t>T$.

Using Eq. 10 again, and noting that $\lim _{t \rightarrow \infty} R_{i t}=r \cdot s_{i}^{2} /\left(1-r \cdot s_{i}\right)=R_{i}$ and that $\phi \cdot r \cdot s_{i}^{2} /\left(1-r \cdot s_{i}\right)<1$ (since there cannot be changes in the ranking of performances $\forall t>T$ ), it can be proved that:

$$
\lim _{t \rightarrow \infty} x_{i t}=x^{\operatorname{Max}}
$$

Thus, in the long run: $x_{i t}=x_{i}=x^{\mathrm{Max}}, \forall i$. Bearing in mind also that in the long run $\gamma_{i t}=\bar{\gamma}_{t}$, we then obtain $p_{i}=\bar{p}, \forall i$. Thus:

$$
\begin{aligned}
p_{i} & =\left(1+s_{i}\right) /\left(1-r \cdot s_{i}\right)=\left(1+s_{j}\right) /\left(1-r \cdot s_{j}\right)=p_{j} \\
& \Rightarrow\left\{0<s_{i}<1\right\} \Rightarrow s_{i}=s_{j}=s=1 / n, \forall i, j .
\end{aligned}
$$

Substituting this last result in the equations derived above, we obtain the 6 propositions (a-f) included in the statement.

\section{Appendix 2}

Given the difficulties involved in an exhaustive computational analysis for all the parameters of the model, ${ }^{18}$ we have taken high cumulativeness in Eq. 10 as an almost permanent assumption. However, it seems reasonable to check-even

\footnotetext{
${ }^{18}$ Not only for the high number of simulations required for a rigorous analysis of a stochastic model like ours, but also - and fundamentally_-for the difficulties associated to the global treatment of the information and the extraction of conclusions from our simulations.
} 


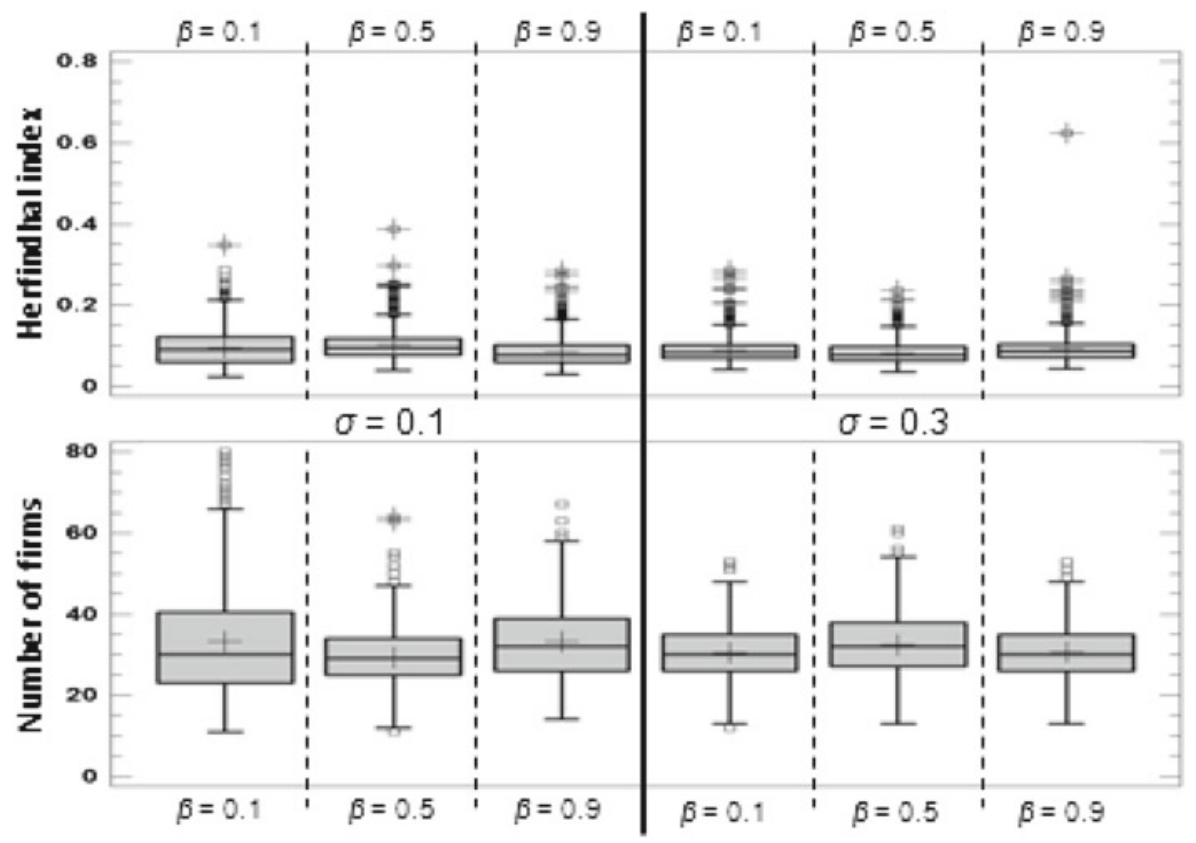

Fig. 10 Box-plots of the Herfindhal index (above) and the number of firms (below) at time step 30,000, for $\alpha=0.5, \lambda=0.1, \phi=0.9, u_{\mathrm{Max}}=0.5, \eta=0.1$ and different values of $\sigma$ and $\beta$. Each box-plot represents data from 1,000 simulation runs

if only provisionally - what would happen to the patterns which emerge from entrepreneurial regimes, if we suppose low cumulativeness.

In Fig. 10 we present the results obtained for the Herfindhal index and the number of firms at $\mathrm{t}=30,000$, for the case of entrepreneurial regimes with $\eta=0.1$, considering the level of technological opportunities is medium, and the demand has an intermediate profile. This parametric configuration allows us to directly compare Fig. 10 with Fig. 5, and thus see how the results change when considering low cumulativeness in entrepreneurial regimes.

As we can see in both figures, the expected results are maintained for the case of low cumulativeness. In this case, we also obtain low levels of industry concentration and a high number of firms in the limit states. This reinforces the results seen in Section 4.1.2 regarding the appearance of creative destruction patterns in entrepreneurial regimes.

\section{References}

Almudi I, Fatas-Villafranca F, Izquierdo LR (2012) Innovation, catch-up and leadership in science-based industries. Ind Corp Change 21(2):345-375

Ariga K, Ohkusa Y, Nishimura KG (1999) Determinants of individual-firm markup in Japan: market concentration, market shares and FTC regulations. J Jpn Int Econ 13(4):424-450 
Bresnahan T, Yin P (2010) Reallocating innovative resources around growth bottlenecks. Ind Corp Change 19(5):1589-1627

Breschi S, Malerba F, Orsenigo L (2000) Technological regimes and schumpeterian patterns of innovation. Econ J 110:388-410

Cohen W, Klepper S (1996) A reprise of size and R\&D. Econ J 106(437):925-951

Dosi G (1988) Sources, procedures and microeconomic effects of innovation. J Econ Lit 26:1120-1171

Dosi G (2001) Innovation, organization and economic dynamics. Edward Elgar, Cheltenham

Dosi G, Nelson RR (2010) Technical change and industrial dynamics as evolutionary processes. In: Hall BH, Rosenberg N (eds) Handbook of the economics of innovation. Elsevier, North-Holland

Dosi G, Marsili O, Orsenigo L, Salvatore R (1995) Learning, market selection and the evolution of industrial structures. Small Bus Econ 7(6):411-436

Fatas-Villafranca F, Saura D (2004) Understanding the demand-side of economic change. Econ Innov New Technol 13(8):695-716

Fatas-Villafranca F, Jarne G, Sanchez-Choliz J (2009) Industrial leadership in science based industries. J Econ Behav Organ 72(1):390-407

Fatas-Villafranca F, Saura D, Vazquez FJ (2011) A dynamic model of public opinion formation. J Public Econ Theory 13(3):417-441

Klepper S (1996) Entry, exit, growth and innovation over the product life cycle. Am Econ Rev 86(3):562583

Klepper S, Malerba F (2010) Demand, innovation and industrial dynamics: an introduction. Ind Corp Change 19(5):1515-1520

Malerba F (2006) Innovation and the evolution of industries. J Evol Econ 16:3-23

Malerba F (2007) Innovation and the dynamics and evolution of industries. Int J Ind Organ 25:675-699

Malerba F, Orsenigo L (1993) Technological regimes and firm behavior. Ind Corp Change 2:45-74

Malerba F, Orsenigo L (1996) Schumpeterian patterns of innovation are technology-specific. Res Policy 25:451-478

Marsili O (1999) Technological regimes: theory and evidence. Dynacom Working Paper. http://www.lem. sssup.it/Dynacom/files/D20_0.pdf

Marsili O (2001) The anatomy and evolution of industries: technological change and industry dynamics. Edward Elgar, Cheltenham

Metcalfe JS (1998) Evolutionary economics and creative destruction. Routledge, London

Nelson RR (1982) The role of knowledge in R\&D efficiency. Q J Econ 97(3):453-470

Nelson RR, Winter SG (1982) An evolutionary theory of economic change. Harvard University Press, Cambridge

Pavitt K, Robson M, Townsend J (1989) Technological accumulation, diversification and organisation in UK companies, 1945-1983. Manag Sci 35:81-99

Romer PM (1990) Endogenous technological change. J Polit Econ 98(5):71-102

Rosenberg N (1976) Perspectives on technology. Cambridge University Press, Cambridge

Silverberg G, Verspagen B (2005) Evolutionary theorizing on economic growth. In: Dopfer K (ed) The evolutionary foundations of economics. Cambridge University Press, Cambridge

Teece DJ (1986) Profiting from technological innovation: implications for integration, collaboration, licensing and public policy. Res Policy 15:285-305

Winter SG (1984) Schumpeterian Competition in alternative technological regimes. J Econ Behav Organ 5:287-320

Winter SG (1987) Knowledge and competence as strategic assets. In: Teece DJ (ed) The competitive challenge. Strategies for industrial innovation and renewal. Ballinger Publishing Company, Cambridge 